\title{
PENGALAMAN PERAWAT TENTANG CARING BERBASIS TEKNOLOGI PADA PASIEN KRITIS DI INTENSIVE CARE UNIT
}

\author{
Lina Anggraeni ${ }^{1}$, Suhartini Ismail ${ }^{2}$ \\ ${ }^{1}$ Mahasiswa Departemen Ilmu Keperawatan, Fakultas Kedokteran, Universitas Diponegoro \\ ${ }^{2}$ Dosen Divisi Keperawatan Dewasa, Sub Divisi Keperawatan Emergensi dan Kritis Departemen Keperawatan, \\ Fakultas Kedokteran, Universitas Diponegoro \\ linaanggraeni27@gmail.com
}

\begin{abstract}
Abstrak
ICU merupakan suatu unit dengan pasien yang menerima perawatan intensif dan monitoring yang ketat. Untuk itu, diperlukan perawat yang terlatih secara khusus dengan menggunakan teknik yang canggih dan dapat memenuhi kebutuhan dasar dari pasien. Dengan membangun keseimbangan antara aspek perawatan pasien dan teknologi, perawat akan dapat memberikan perawatan yang lebih efisien dengan kualitas yang lebih tinggi. Penelitian ini bertujuan untuk mendeskripsikan pengalaman perawat tentang caring berbasis teknologi pada pasien kritis di intensive care unit. Penelitian ini merupakan penelitian kualitatif dengan pendekatan deskriptif fenomenologi. Penelitian dilakukan di Himpunan Perawat Critical Care Jawa Tengah. Partisipan penelitian sebanyak 10 perawat yang ditentukan dengan metode purpose sampling. Pengumpulan data dilakukan melalui wawancara mendalam kepada partisipan selama 40-60 menit sesuai dengan pedoman wawancara yang telah disusun sebelum penelitian. Data yang terkumpul dianalisa menggunakan metode Colaizzi. Hasil penelitian menghasilkan tiga tema yaitu kompetensi penggunaan teknologi menjadi bagian dari caring yang harus dimiliki perawat, keseimbangan perilaku caring dan kompetensi teknologi perawat di ruang pelayanan kritis, serta maleficient dan beneficient. Perawat ICU harus berperilaku caring yang ditunjukkan dengan memiliki kompetensi yang tinggi pada penggunaan teknologi agar terciptanya perawatan yang lebih baik untuk pasien kritis.
\end{abstract}

Kata kunci: Caring berbasis teknologi, perawat ICU, pasien kritis, intensive care unit

\begin{abstract}
The nurses' experiences of technologybased caring in critical patients in the intensive care unit. Intensive Care Unit (ICU) is a unit in which patients receive intensive care and strict monitoring. For this reason, nurses who are specifically trained to use sophisticated techniques and able to meet the basic needs of patients are needed. By developing a balance between the aspects of patient care and technology, nurses will be able to provide more efficient care with higher quality. This study aimed to describe the nurses' experiences of technology-based caring in critical patients in the intensive care unit. This study was qualitative research with a descriptive phenomenological approach conducted at the Critical Care Nurse Association of Central Java. The participants were ten nurses selected by using purposive sampling technique. The data were collected through in-depth interviews with the participants for 40-60 minutes based on the prepared interview guidelines. The collected data were analyzed using the Colaizzi method. The results showed three themes that technological competence to be part of the caring that nurses must have, the balance between nurses' caring behaviors and technological competence in the critical area, then, maleficient and beneficient. Nurses should behave caring which is shown by having high competence using of technology to provide better care for critical patients.
\end{abstract}

Keywords: Caring based on technology, critical nurse, critical patient, intensive care unit

\section{Pendahuluan}

ICU adalah salah satu ruang atau unit di rumah sakit yang mana pasien menerima perawatan intensive dan mendapatkan monitoring yang ketat (Darmayanti \& Oktamianti, 2014). Unit perawatan intensif bertujuan untuk merawat pasien yang sakit parah oleh perawat yang terlatih secara khusus dengan menggunakan teknik yang canggih (Sabzevari \& Mirzaei, et al., 2015). Survey kepada 685 perawat di
Belanda menunjukkan bahwa terdapat setengah dari $67 \%$ perawat yang menanggapi, perawat menilai secara positif terhadap pengenalan teknologi baru dalam tiga tahun terakhir (Isabelle, 2011). Selain itu, teknologi dapat mempersulit pekerjaan perawat karena kurangnya pengetahuan dan kompetensi untuk menafsirkan semua data yang diterima dari teknologi mesin itu sendiri (Sabzevari \& Mirzaei, et al., 2015). 
Penelitian McGrath (2008) melakukan wawancara kepada 10 perawat berpengalaman dari 2 unit perawatan kritis kardiotoraks di Irlandia dengan hasil bahwa studinya memberikan pandangan optimis/pesimis terhadap teknologi keperawatan dan teknologi mendukung kehidupan pasien kritis sehingga dapat membawa pengalaman sangat dekat dengan pasien dan keluarga pasien. Perawat membutuhkan tingkat keterampilan dan pengetahuan yang lebih tinggi untuk penggunaan teknologi yang semakin maju, tingkat selanjutnya agar lebih fokus pada inti dasar caring (Adams, 2016). Hal tersebut dengan pertimbangan bahwa teknologi dapat melakukan banyak hal untuk pasien seperti fisik dan fisiologis namun tidak termasuk emosional, spiritual dan psikologis seperti yang dibutuhkan (Adams, 2016).

Penelitian Bagherian \& Sabzevari dkk (2017) di sebuah rumah sakit di Iran menunjukkan bahwa terdapat sampel 200 perawat perawatan kritis mengenai pendapat tentang pengaruh teknologi terhadap tindakan keperawatan caring menunjukkan sampel perawat tersebut memiliki pendapat positif mengenai pengaruh teknologi pada praktik perawat dengan anggapan bahwa teknologi memfasilitasi dan meningkatkan perawatan pasien, membantu perawat mengendalikan lingkungan kerja mereka dan mengarah pada promosi profesi keperawatan (Bagherian \& Sabzevari, dkk., 2017). Penelitian Bagherian \& Sabzevari dkk pada tahun 2017 dengan fenomenologi hermeneutik di Rumah Sakit di Iran, terdapat penelitian mengenai pengalaman hidup perawat perawatan kritis dalam caring di lingkungan teknologi kepada 9 perawat ICU perawat dalam perilaku caring di ICU sebagai proses holistik yang membutuhkan kewaspadaan perawat mengenai semua aspek kebutuhan pasien dan berusaha untuk mencapainya, sementara pada saat yang bersamaan, menjadi kompeten dan ahli dalam bekerja dengan alat teknis tingkat lanjut (Bagherian \& Sabzevari, dkk., 2017). Berdasarkan latar belakang tersebut, penelitian bertujuan mendeskripsikan pengalaman perawat tentang caring berbasis teknologi pada pasien kritis di Intensive Care Unit.

\section{Metode}

Desain penelitian ini adalah kualitatif dengan pendekatan deskriptif kualitatif. Teknik pengambilan sampel adalah purposive sampling, dengan kriteria inklusi usia lebih dari 21 tahun, pernah bekerja pada area kritis selama minimal 2 tahun atau lebih, pendidikan D3/S1/S2. Besar sampel adalah 10 orang partisipan yang tergabung dalam HIPERCCI (Himpunan Perawat Critical Care Indonesia) Jawa tengah. Data diambil berdasarkan pedoman wawancara yang telah disusun peneliti, menggunakan indepth interview semi terstruktur yang terdiri dari beberapa pertanyaan terkait caring berbasis teknologi. Validasi data menggunakan triangulasi teori. Data yang terkumpul dianalisis menggunakan metode Colaizzi. Pengambilan data dilakukan pada Mei 2018. Penelitian dinyatakan laik etik oleh Komisi Etik Penelitian Kesehatan RSUD Dr Karyadi dengan nomor 292/EC/FKRSDK/V/2018.

\section{Hasil \\ Karakteristik Demografi Partisipan}

Sepuluh orang perawat ruang rawat intensif telah berpartisipasi dalam penelitin ini dengan rentang usia yaitu 25-56 tahun, berpendidikan D3 dan S1, masa kerja lebih dari 2 tahun, jenis kelamin laki-laki 4 orang dan perempuan 6 orang. 
Tabel 1.

Karakteristik Demografi Partisipan

\begin{tabular}{cccccc}
\hline $\begin{array}{c}\text { Inisial } \\
\text { nama }\end{array}$ & $\begin{array}{c}\text { Usia } \\
\text { (tahun) }\end{array}$ & $\begin{array}{c}\text { Pendidik } \\
\text { an }\end{array}$ & $\begin{array}{c}\text { Masa kerja } \\
\text { (tahun) }\end{array}$ & Pelatihan & Jenjang karir \\
\hline Ny.L & 38 & D3 & 10 & BTCLS, ICU & PK 3 \\
Ny.N & 56 & S1 & 20 & BTCLS, ICU & PK 3 \\
Ny.A & 25 & S1 & 2 & BTCLS, ICU & PK 1 \\
Tn.W & 37 & S1 & 10 & BTCLS, ICU, & PK 3 \\
& & & & Kardiologi Dasar, & \\
Ny.D & 34 & D3 & 10 & ACLS & PKCLS, ICU \\
Ny.W & 53 & S1 & 15 & BTCLS, ICU & PK 3 \\
Ny.E & 30 & D3 & 7 & BTCLS, ICU & PK 2 \\
Tn.P & 38 & S1 & 16 & BTCLS, ICU & PM \\
Tn.F & 36 & S1 & 6 & BTCLS, ICU & PK 3 \\
Tn.A & 40 & S1 & 15 & BTCLS, ICU, & PK 3 \\
& & & & Ventilator, & \\
\hline
\end{tabular}

Keterangan: ICU (Intensive Care Unit), BTCLS (Basic Trauma Cardiac Life Support), TPPK (Tenaga Pelatih Program Kesehatan), ACLS (Advanced Cardiac Life Support)

\section{Kompetensi penggunaan teknologi menjadi bagian dari caring yang harus dimiliki perawat}

Kompetensi teknologi perawat meliputi strategi meningkatkan kompetensi teknologi dan kompetensi penggunaan teknologi berdampak positif untuk pasien. Partisipan mengungkapkan bahwa strategi dalam meningkatkan kompetensi dalam teknologi meliputi pelatihan ICU, pemanfaatan clinical research untuk mengetahui dan memecahkan masalah kondisi pasien di ICU, terlibat aktif dalam diskusi, untuk menambah pengetahuan dengan sharing knowledge oleh perawat yang lebih berpengalaman dan senior, adanya kemauan atau keinginan untuk terus belajar, membaca buku instruksi atau panduan dari alat secara mandiri, mengaplikasikan langsung penggunaan teknologi kepada pasien.

"perawat yang mengikuti pelatihan ICU memiliki skill yang berbeda dengan

perawat yang tidak mengikuti pelatihan" $(P 9)$

"ketika di ICU membutuhkan pemecehan kasus dari pasien kami dapat mencari dan memakai jurnal dalam mengatasi hal tersebut." $(P 10)$

"setiap konferen kita melakukan review ulang mengenai pasien maupun pengoperasian alat agar perawat tidak lupa dan dapat merefresh kembali ilmunya, kami juga bergabung diskusi dengan himpunan agar dapat mempelajari hal-hal yang masih trend" $(P 4)$

"menurut saya ada kemauan untuk belajar, memiliki rasa ingin tahu yang tinggi sehingga menuntut kita untuk terus belajar meningkatkan ilmu, jangan malu untuk bilang tidak bisa, jangan malu untuk nanya, jangan malu untuk belajar dari siapapun."(P3)

"menurut saya teknologi adalah alat yang dapat dipelajari secara manual melalui buku manual yang menyertai alat tersebut seperti bagaimana caranya, tujuannya untuk apa sehingga kita dapat menyesuaikan dalam penggunaannya" (P2)

"jika kita tidak memakaikan alat tersebut kepada pasien, kita tidak akan tahu bagaimana perlakuan alat tersebut apalagi 
jika dikaitkan dengan respon pasien maka kita harus mencobanya kepada pasien “(P2)

Partisipan mengungkapkan bahwa perawat yang paham dalam teknologi dapat menjadikan pasien dalam keadaan yang aman dan tidak membahayakan pasien, serta dapat membuat kondisi pasien menjadi lebih baik.

"ICU identik dengan penggunaan teknologi tingkat tinggi sehingga bagaimana cara kita memelihara saat alat aman dipakai pasien... sebagai perawat harus tahu dalam pengoperasian alat, jangan sampai alat yang kita berikan kepada pasien tidak aman pastikan alat tersebut safety untuk pasien. "(P1)

"alat akan membantu kita bekerja sehingga perawat praktis dalam bekerja juga dapat membantu pasien dalam hal proses perawatan dan penyembuhan. “(P4)

\section{Keseimbangan perilaku profesional perawat dengan kompetensi pada teknologi di ruang pelayanan kritis}

Partisipan menjelaskan bahwa teknologi sebagai bagian dari pendukung perilaku caring dalam perawatan pasien. Teknologi hanya sebagai menolong, membantu, penunjang dan tambahan bukan sebagai pengganti peran perawat.

"Menurut saya teknologi hanya menolong, tapi kepedulian tetap nomer satu...kompetensi teknologi hanyalah bagian dari kompetensi perawat, perawat adalah memahami kebutuhan pasien yang ditolong dengan kemampuan terkini yaitu teknologi“ $(P 2)$

Hasil yang muncul dari adanya teknologi disesuaikan dengan respon klinis dari pasien, sehingga perawat harus mempertimbangan dan memahami respon pasien yang menggunakan teknologi. "tidak ada gunanya paham teknologi tapi tidak peduli dengan kebutuhan atau tanggap dengan permasalahan pasien, apabila perawat tidak memahami respon pasien maka tidakakan matching " $(P 2)$

Perawat harus memenuhi kebutuhan dasar pasien kritis secara holistic (biopsiko-sosio-kul-spiritual).

"pasien kritis memiliki gangguan fungsi organ yang cukup signifikan yang berpotensi mengancam jiwa sehingga secara fisik memang dominan membutuhkan pengelolaan untuk pemenuhan kebutuhannya serta masalahmasalah yang lain seperti psikis, spiritual dan yang lain yang perlu dikelola dan diperhatikan" $(P 2)$

Perubahan yang dialami pada perawat dalam meyeimbangkan perilaku caring dan kompetensi teknologi yaitu perawat menjadi lebih percaya diri sehingga tindakan yang dilakukan perawat jelas dan tepat kepada pasien.

"perubahan saat kita melakukan perawatan dan pasien menjadi lebih baik setelah kita melakukan perawatan, tentu ada penambahan percaya diri sehingga akan menambah keinginan kita untuk terus belajar" (P10)

Partisipan menyatakan bahwa dari efek adanya high technology menjadikan perawat timbul sifat malas dalam melakukan perawatan kepada pasien.

“teknologi memang meringankan kerja perawat, namun efek negatifnya adalah malas yang akan menjadikan skill kita tumpul "(P4)

Namun, partisipan menyatakan bahwa adanya teknologi, sebagai perawat harus meminimalkan ketergantungan yang muncul dari efek negatif teknologi sehingga lebih fokus pada perawatan yang baik kepada pasien. 
"menurut saya, bergantung dengan mesin tidak akan baik karena kita akan terfokus hanya dengan teknologi sehingga seni merawat kita akan hilang "(P9)

\section{Maleficient dan Beneficient}

Perawat dalam melakukan perilaku caring dan kompetensi teknologi muncul beberapa hal yang menghambat atau ketidaknyamanan perawat dalam caring berbasis teknologi sehingga dibutuhkan perawat yang dapat mengambil langkah positif untuk meminimalkan hambatan yang ada. Berdasarkan tema maleficient dan beneficient, peneliti menentukan sub tema yaitu alat dan sarana yang kurang lengkap untuk mendukung caring berbasis teknologi, persepsi keluarga pasien terhadap penerapan teknologi, caring berbasis teknologi didasari oleh diri perawat, dan kurang adanya dukungan teman sejawat.

"terdapatnya factor alat yang tidak mendukunng dalam perwatan kepada pasien sehingga kami tidak dapat melakukan perwatan kepada pasian dan akhirnya kami harus merujuk pasien "(P10)

"problematika muncul dalam membahas kondisi pasien kepada keluarga, namun penerimaan keluarga terhadap kondisi pasien kritis dinamis sekali beda-beda sehingga kami perlu memberikan edukasi yang lebih" $(P 2)$

"Manusia memiliki mood masing-masing dan menjaga mood itu susah dan sebagai perawat ICU memiliki pressure yang tinggi sehingga sewaktu-waktu dapat menurunkan mood apabila mood sudah tidak baik mau melakukan apapun akan malas"(P3)

"muncul komentar kurang mengenakan dari teman saya terkait dengan perawatan yang saya lakukan kepada pasien”(P7)
Partisipan menyatakan bahwa perlu adanya strategi dalam menanggulangi hambatan yang muncul seperti meningkatkan pemahaman mengenai trouble shooting, melakukan pemantauan alat secara berkala,

"perawat harus memahami trouble shooting ketika ada alarm atau eror pada alat, ada buku panduan untuk dapat membantu kita memahami trouble shooting, jika belum bisa teratasi secara mandiri maka segera mengkomunikasikan kepada teknisi.”(P2)

“Teknologi yang ada di ICU ada pemantauan dan pengecekan alat oleh perawat, jika mengindikasikan eror maka perawat harus segera memanggil petugas elektromedik agar segera tertangani dengan benar dan dapat digunakan kembali."(P3)

"jika mood saya masih kurang bagus, saya akan melibakan tim, karena biasanya dengan menciptakan suasana tim yang enak maka suasana kerja menjadi ringan dan mood akan kembali baik.”(P3)

“...selain itu, kurang tidur dapat mempengaruhi mood sehingga kita harus menjaga stamina, perbaiki jam tidur supaya istirahatnya cukup sehingga kerja pun juga bagus."(P5)

\section{Pembahasan \\ Pengalaman Perawat tentang Caring Berbasis Teknologi pada Pasien Kritis di Intensive Care Unit}

Kompetensi teknologi merupakan aspek penting yang dapat mempengaruhi perawat dalam memberikan perawatan kepada pasien kritis. Peningkatan kompetensi teknologi dapat didukung dengan mengikuti training karena pelatihan mampu memperbaiki dan meningkatkan skill perawat dalam perawatan kepada pasien kritis, hal ini sesuai dengan penelitian Samaher (2011) yang menjelaskan bahwa perawat yang terlatih dalam penggunaan perangkat 
teknologi memiliki pengalaman dan persepsi yang jauh lebih positif dari pengaruh teknologi pada perawatan klien. Perawat yang melakukan strategi untuk meningkatkan kompetensi penggunaan pada teknologi dapat berdampak positif pada pasien yang mempengaruhi kenyamanan dan kondisi pasien menjadi lebih membaik. Hal ini didukung pendapat Locsin (2007) yang menjelaskan bahwa melalui penggunaan kompetensi yang kompeten dapat meningkatkan kemampuan perawat dalam hal untuk mengetahui, merawat, dan dapat menghadirkan diri kepada pasien.

Hasil penelitian menunjukkan bahwa partisipan menganggap penggunaan teknologi merupakan bagian yang dapat menunjang perilaku caring perawat terhadap pasien, hal ini sesuai dengan penelitian McGrath tahun 2008 menjelaskan bahwa teknologi dianggap sebagai fasilitator praktik. Penelitian lainnya dari Bagherian \& Sabzevari dkk tahun 2017 menyatakan bahwa kehadiran teknologi tidak mengurangi pentingnya perawatan. Pada penelitian ini, persepsi perawat bahwa teknologi dibutuhkan sebagai tambahan dalam proses keperawatan yang mana perawat mempersepsikan positif adanya teknologi, hal ini sesuai dengan penelitian Bagherian \& Sabzevari dkk tahun 2017 bahwa salah satu faktor pengaruh teknologi pada asuhan keperawatan dan caring perawat kritis yaitu sikap dan persepsi perawat yang juga dapat mempengaruhi pendapat terhadap teknologi dalam keperawatan. Partisipan menyatakan bahwa perlu mengedepankan klinis pasien, hal ini sesuai dengan penelitian Bagherian \& Sabzevari dkk pada tahun 2017 menyatakan perawat harus memperhatikan semua hal lainnya seperti penampilan pasien jika pasien telah membiru di wajah atau tidak dan kondisi klinis pasien yang merupakan pemverifikasi utama keakuratan data yang diterima dari peralatan teknologi.

Respon pasien termasuk dalam aspek yang dapat dilihat secara fisik pada pasien yang mana perawat memiliki kewajiban dalam pemenuhan kebutuhan dasar pasien kritis yang harus diperhatikan sehingga dapat tercukupi dengan baik, hal ini sesuai dengan penelitian Samaher pada tahun 2011 menyatakan perawat percaya bahwa untuk menjadi perawat yang peduli dalam lingkungan teknologi, perawat harus terbuka mengenai kebutuhan bio-psikososial dan spiritual pasien. Terpenuhinya kebutuhan dasar pasien yang didukung dengan kompetensi teknologi dan perilaku caring perawat, muncul perubahan yang dialami perawat dalam menyeimbangkan perilaku caring dan teknologi dimana perawat menjadi lebih percaya diri dalam melakukan tindakan perawatan kepada pasien kritis. Perawat yang menggunakan teknologi dengan baik mampu meningkatkan kepercayaan dirinya dan meningkatkan kompetensinya dalam memenuhi kebutuhaan perawatan pasien (Greger, 2012).

Hasil penelitian menunjukkan bahwa partisipan lebih memilih untuk meminimalkan efek negatif penggunaan teknologi dimana pendapat tersebut mengartikan bahwa perawat tidak harus mengandalkan mesin dan teknologi dalam perawatan pasien, hal ini sesuai dengan penelitian Bagherian \& Sabzevari dkk pada tahun 2017 menyatakan jika data yang disediakan oleh peralatan teknologi membutuhkan interpretasi akurat oleh perawat karena perawatan yang berkualitas melengkapi teknologi, memfasilitasi proses pemulihan pasien yang bergantung pada teknologi, hal sebaliknya juga terjadi, karena kelalaian dalam perawatan atau ketergantungan sepenuhnya pada teknologi membuat teknologi menjadi tidak berguna.

Perawat dalam menerapkan caring berbasis teknologi pada perawatan pasien kritis mengalami halangan atau ketidaknyamanan yang terdiri dari alat dan sarana yang kurang lengkap untuk mendukung caring berbasis teknologi, persepsi keluarga pasien terhadap penerapan teknologi, caring berbasis teknologi didasari oleh diri perawat, dan 
kurang adanya dukungan teman sejawat. Perawat dalam penerapan caring berbasis teknologi memiliki adanya perubahan emosional atau mood dan latar belakang sebelum masuk kerja sehingga dapat mempengaruhi perawat dalam melakukan perawatan kepada pasien. Faktor yang berhubungan dengan caring perawat kepada pasien salah satunya yaitu faktor personal yang mengacu pada pribadi perawat itu sendiri seperti lama pengalaman kerja, pelatihan, kesadaran diri dan distress (Kusumarini, 2016). Selain itu, adanya perbedaan pola pikir dan cara kerja dari teman sejawat memunculkan tanggapan negatif seperti opini teman dengan komentar yang tidak enak, sesuai dengan penelitian Bagherian \& Sabzevari dkk pada tahun 2017 menyatakan beberapa peserta melaporkan ketakutan diejek oleh teman sebaya sebagai halangan untuk menyediakan layanan perawatan termasuk berbicara kepada pasien yang tidak sadar, menjelaskan kondisi mereka kepada mereka, dan menyentuh mereka. Maka faktor lingkungan tempat kerja berperan penting dalam memberikan perawatan yang berkualitas (Kusumarini, 2016).

Perawat harus memiliki strategi dalam menanggulangi halangan atau ketidaknyamanan saat melakukan caring berbasis tekologi seperti peningkatan pemahaman perawat mengenai trouble shooting dan pemantauan alat secara berkala, perawat dapat memperbaiki suasana hati atau mood dengan bergabung bersama teman sejawat dan menciptakan suasana yang nyaman, perawat mengibaratkan terjadinya konflik internal sebagai cara pendewasaan diri, serta perawat harus menjaga stamina dengan memperbaiki pola tidur sehingga perawat dapat melakukan perawatan yang baik kepada pasien.

\section{Simpulan dan Saran}

Penelitian ini didapatkan bahwa kompetensi perawat sangat penting untuk menunjang perawatan dan kesembuhan pasien kritis. Sebaiknya perawat selalu meningkatkan pengetahuan, kemampuan dan melatih kompetensi teknologi dengan tetap meyeimbangkan perilaku caring guna memahami pasien dan melakukan perawatan kepada pasien kritis dengan baik

\section{Daftar Pustaka}

Sabzevari S, Mirzaei T, Bagherian B, Iranpour M. Critical Care Nurses' Attitudes about Influences of Technology on Nursing Care. Br J Med Med Res. 2015;9(8):1-10.

Barnard A, Locsin R. Technology and Nursing: practice, concepts, and issues. New York: Palgrave Macmillan; 2007.

Isabelle Szmigin GF. Successful implementation of new technologies in nursing care: a questionnaire survey of nurse-users. BMC Med Inform Decis Mak. 2011;11(1):1-12.

McGrath M. The challenges of caring in a technological environment: Critical care nurses' experiences. J Clin Nurs. 2008;17(8):1096-104.

Bagherian B, Sabzevari S, Mirzaei T, Ravari A. Effects of technology on nursing care and caring attributes of a sample of Iranian critical care nurses. Intensive Crit Care Nurs. 2017;39:18-27.

Price AM. Caring and technology in an intensive care unit: An ethnographic study. Nurs Crit Care. 2013;18(6):278-88.

Bagherian B, Sabzevari S, Mirzaei T, Ravary A. Meaning of Caring from Critical Care Nurses' Perspective: A Phenomenological Study. iMedPub Journals J Intensive Crit Care. 2017;3(3):1-9.

Korhonen ES, Nordman T, Eriksson K. Technology and its ethics in nursing 
and caring journals: An integrative literature review. Nurs Ethics. 2015;22(5):561-76.

Greger J. Master of Arts in Nursing Theses Facilitating Caring Behaviors in Technology- Dependent Nursing Practice Through the use of Simulation Training and Confluent Education Strategies. 2012

Locsin RC. Machine Technologies and Caring in Nursing. Image $\mathbf{J}$ Nurs Scholarsh. 1995;27(3):201-3.

Kusumarini E. Faktor-faktor yang mempengaruhi perilaku caring perawat di ruang sulaiman 3-4 RS Roemani Muhammadiyah Semarang. 2016

Samaher A. Laila NTMAMMAM. Nurses' Perception Regarding the Use of Technological Equipment in the Critical Care Units. $2011 ; 7(10): 42-4$.

AACN. Competencies and Curricular Expectations for Clinical Nurse Leader Education and Practice. 2013

Shosha G. Employment of Colaizzi'S Strategy in Descriptive Phenomenology: a Reflection of a Researcher. Eur Sci J. 2012;8(27):31-43. 